\title{
APPLICATION AND EFFICACY TEST OF SIRNA VACCINE AGAINST NERVOUS NECROSIS VIRUS INFECTION
}

\author{
Feng Jie Su, and Ming-Wei Lu ${ }^{\S}$ \\ Department of Aquaculture, National Taiwan Ocean University. Keelung 20224, Taiwan.
}

\begin{abstract}
Nervous necrosis virus (NNV) could infect many economic fish species and cause the fish nervous tissue necrosis vacuolization in histopathology. Once the fish is infected with NNV, 80-100\% mortality will occour in grouper breeding farm. However, the immune system does not develop completely in grouper larva. Therefore, the traditional vaccine may not be effective during larva stage. This study applied siRNA interference technique against NNV in large scale field trail. The siRNA was delivered into grouper's brain and eye by oral administration. The expression of siRNA could reduce the virus titer and increase the survival rate of grouper larva. By feeding RNAi to NNV infected grouper, the overall breeding rate increased and reached $48 \%$ in NNV outbreak farm. Therefore, this technique has a very high application capability in grouper aquaculture industry
\end{abstract}

KEYWORDS: NNV, siRNA, grouper, vaccine, RNAi

$\S$ Corresponding author. Tel. +886-2-2462-2192\#5206; Fax: +886-2-2462-0724

E-mail address: mingwei@ntou.edu.tw 